\title{
A Case of Aluminum Nitride Embrittlement of Heavy Wall Cast Steel
}

\author{
J. Maciejewski $\cdot$ C. Regulski
}

Submitted: 5 September 2017/Published online: 23 October 2017

(C) ASM International 2017

\begin{abstract}
Weld cracking was observed in multiple heats of large-sized cast steel components. Fracture analysis, metallography, and mechanical testing indicated that the failure mechanism was aluminum nitride (AlN) embrittlement. Prevention of this type of embrittlement is achieved by controlling aluminum content, nitrogen content, and above all, cooling rate of the casting. A macro-etch procedure for evaluating large castings for AlN embrittlement has been available in ASTM A 703 for decades, and it was found to adequately predict embrittlement in this instance.
\end{abstract}

Keywords Aluminum nitride embrittlement .

AlN embrittlement - Cast steel - Steel embrittlement .

Aluminum nitride · ASTM A 703 - ASTM A703

\section{Background}

A manufacturer of heavy machinery reported weld cracking of cast modified AISI 8627 steel pressure-retaining castings during assembly. The cracking was discovered only after multiple failed leak tests and subsequent dye penetrant testing. Some of the samples obtained for laboratory testing had been unsuccessfully weld repaired over the original weld cracks.

The castings were being imported from a second tier supplier. Multiple heats of two casting designs exhibited the problem, herein designated Type 6 and Type 9. The latter was

J. Maciejewski $(\bowtie) \cdot$ C. Regulski

Applied Technical Services, Inc., Marietta, GA, USA

e-mail: jmac@atslab.com heavier and of greater wall thickness. The castings were on the order of 20-40 kg each. Major wall thicknesses were in the range of 25-75 $\mathrm{mm}$. The details of the product and design are withheld for confidentiality reasons. A typical view of the cracking after welding and dye penetrant testing is shown in Fig. 1. Multiple crack paths are visible, relating to the thermal contraction and residual stress patterns of the weldment.

\section{Failure Analysis}

Typical castings were obtained, and areas of interested were sectioned from the castings. The fracture surfaces of the cracks were opened in the laboratory and examined with optical microscopy and scanning electron microscopy (SEM). The fracture surfaces exhibited large flat facets, on the order of $2.5-5 \mathrm{~mm}$ dimensions (Fig. 2.). The size of these facets is much too large to correspond to the prior austenite grain boundaries associated with the immediately preceding heat treatment or weld transformation, which would be on the order of $0.0045 \mathrm{~mm}$ for ASTM grain size number 6 [1]. The appearance of the fracture surface is typically described as "rock candy" and has been associated with aluminum nitride (AlN) embrittlement of steel castings in the past [2-7]. Therein, the large size of the grain facets is due to fracture along the original primary solidification austenite grains or dendrites (as-cast), not the immediate prior austenite grain boundaries. A typical tensile specimen fracture appearance is shown in Fig. 3; this sample exhibited nearly $100 \%$ brittle fracture appearance and is a good example of the rock candy fracture surface.

Metallurgical sections were prepared through several castings according to standard laboratory techniques. The core microstructures consisted of bainite/ferrite mixtures (Fig. 4), while the heat affected zones (HAZ) and weld 


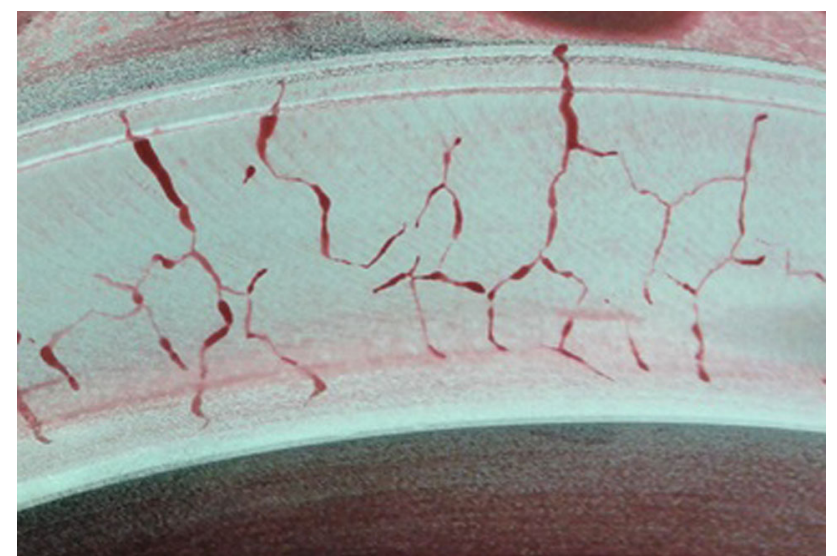

Fig. 1 Cracking identified by liquid penetrant testing

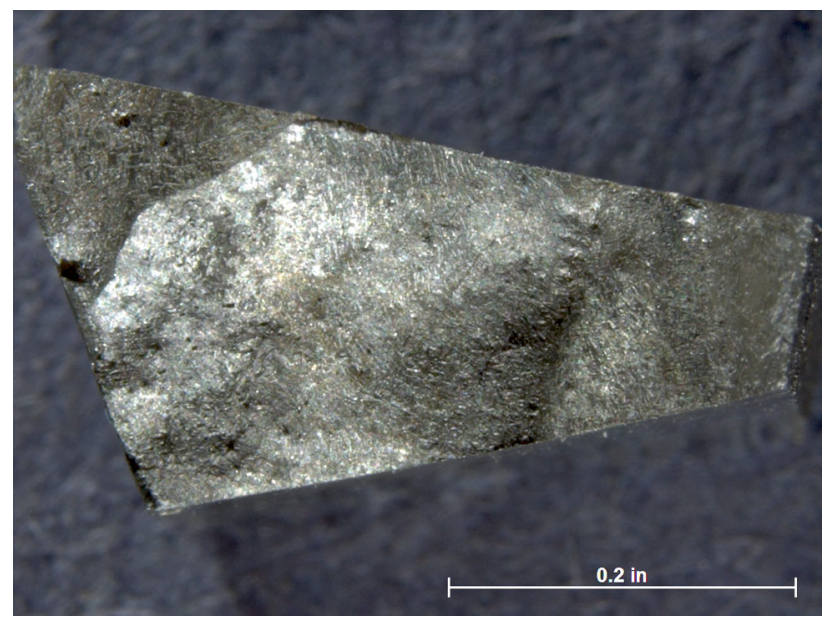

Fig. 2 Portion of the crack surface opened, showing rock candy fracture facets of large size

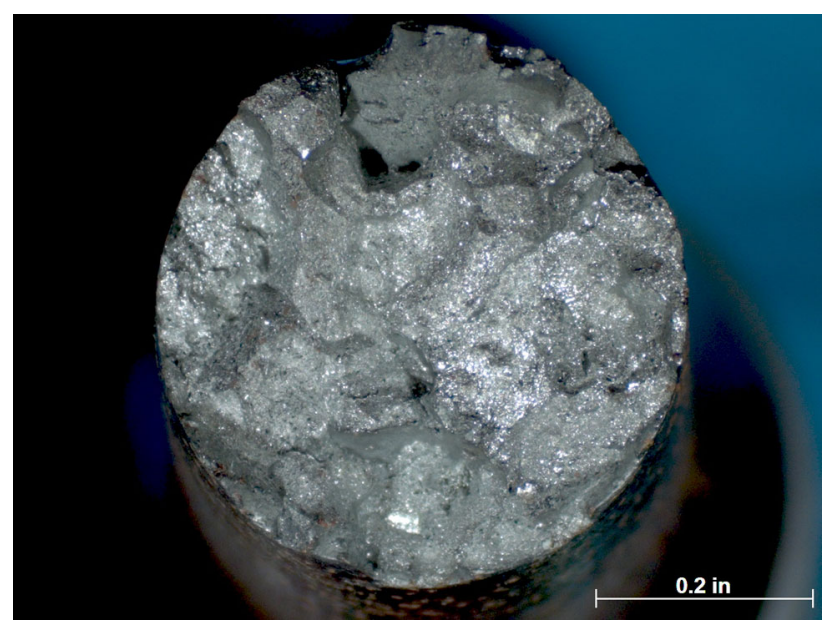

Fig. 3 Brittle tensile specimen fracture surface

metals exhibited martensite with some bainite (Fig. 5). The cracks initiated in the weld metals or HAZ's and propagated in long straight paths into the base material (Fig. 6).

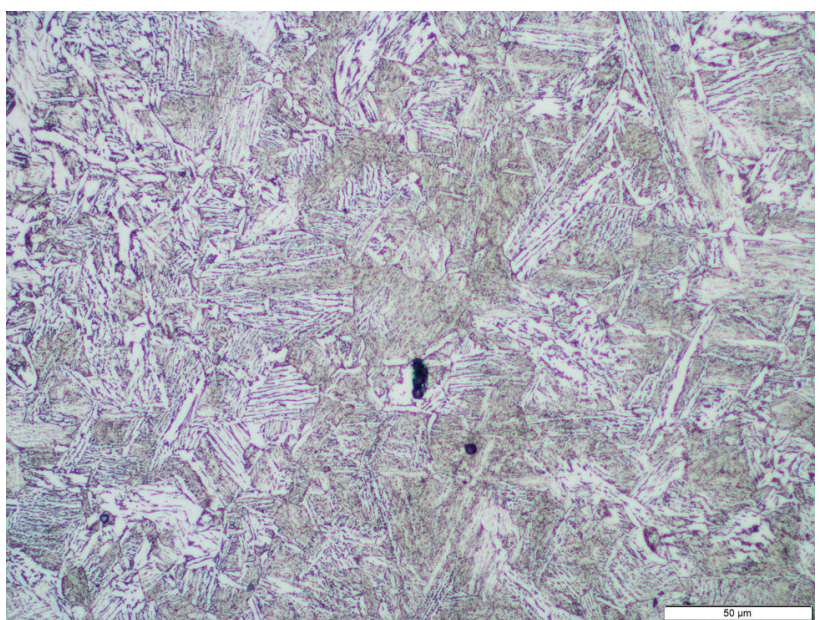

Fig. 4 Typical core microstructure of bainite and ferrite, Nital etchant

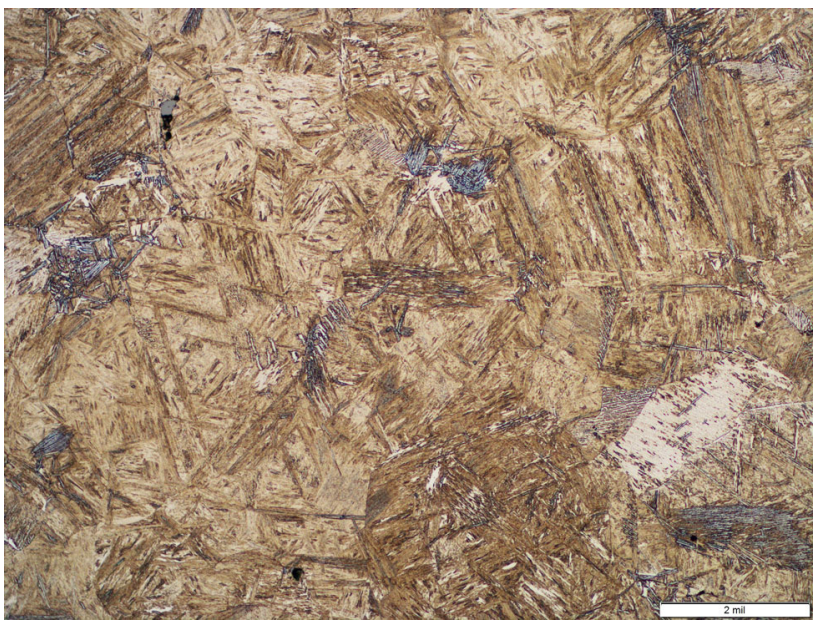

Fig. 5 Typical weld heat affected zone, exhibiting a martensitic microstructure with some bainite, Nital etchant

Martensite in the welds is almost always undesirable and indicates an unqualified weld was performed. This indicates other issues with the manufacturing process; however, it does not alone explain the rock candy fractures that extended into the base material. A martensitic microstructure is more susceptible to aluminum nitride embrittlement [3].

Typical casting fracture surfaces and tensile specimen fracture surfaces were examined at higher magnifications with a scanning electron microscope (SEM). A typical crack surface is shown at various magnifications in Fig. 7. The facets exhibited a characteristic pattern of cross-hatched platelet morphology. This is typical of aluminum nitride embrittlement $[2,6]$ and distinguishes it from other forms of embrittlement such as temper embrittlement, tempered martensite embrittlement, and hydrogen embrittlement [6], which would exhibit relatively flat facets. The 


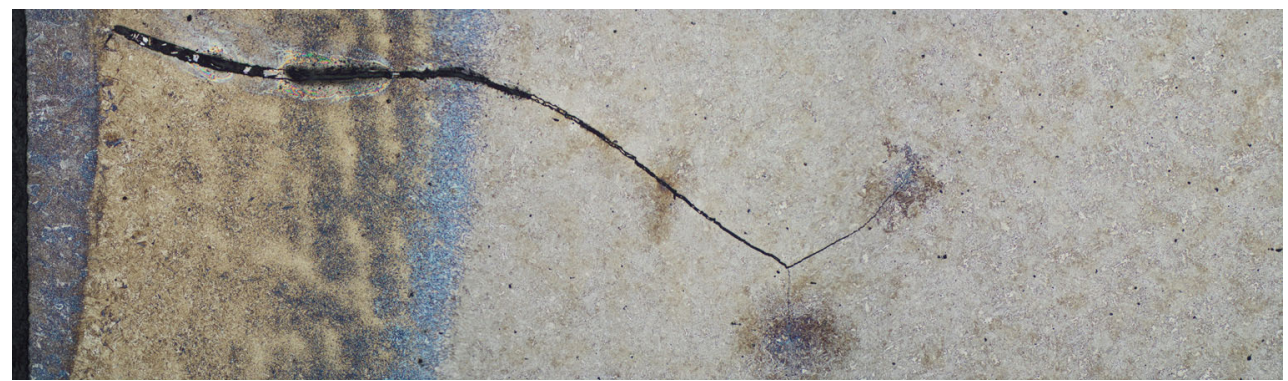

Fig. 6 Typical crack path from HAZ into the base metal, Nital etchant. This crack had a repair weld attempted (at left), which is the source of the additional HAZ and no crack at the surface. Original magnification $25 \times$
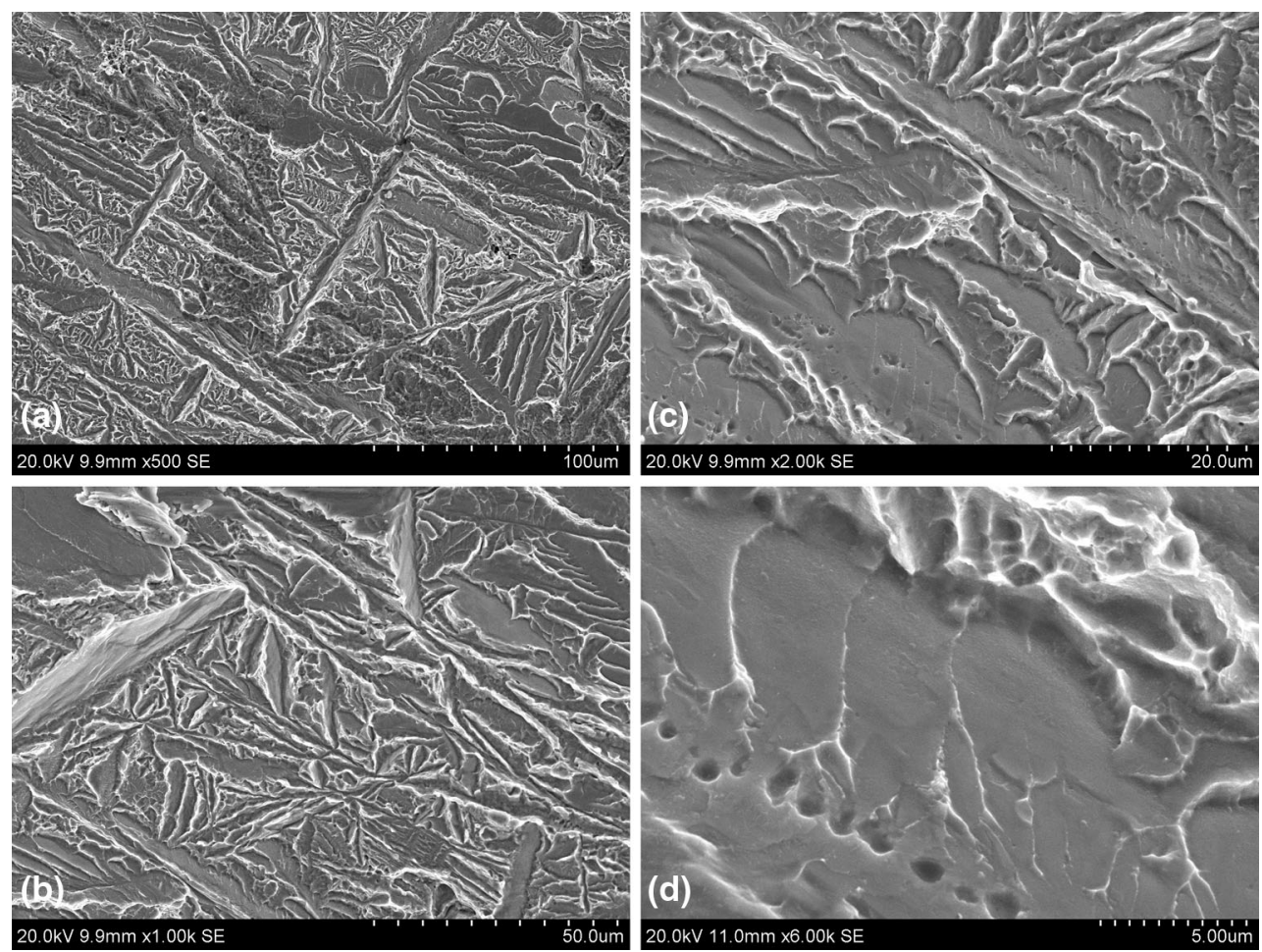

Fig. 7 Typical SEM images of a casting crack surface at various magnifications

platelets are due to the AlN particles that form a semicontinuous network along the primary austenite solidification grain boundaries [2-5, 7]. Micro-scale ductility in the form of small dimples was visible between the platelet locations. The tensile specimen fracture surfaces exhibited similar platelet morphologies (Fig. 8).

Elemental analysis of the fracture surface platelets by energy-dispersive spectroscopy (EDS) could not reliably show increased aluminum concentrations relative to bulk analysis, and nitrogen is not detected with sufficient signal strength by the EDS method to be meaningful. Similarly, attempts at elemental mapping by EDS of the facets indicated no increased contrast due to aluminum in the platelet areas. This is typical of aluminum nitride embrittlement, because the AlN platelets or films are too thin to develop

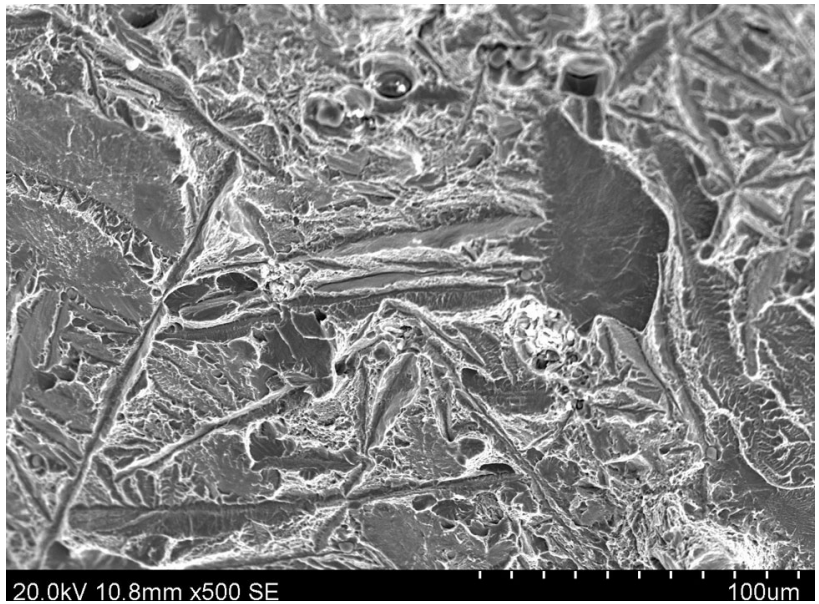

Fig. 8 Typical SEM image of a tensile specimen fracture surface 
sufficient signal with the EDS technique [2]. X-ray photoelectron spectroscopy (XPS) may be necessary to detect these AlN particles since it is a more surface-sensitive technique. XPS was not available to the laboratory for this analysis.

General chemical analyses by optical emission spectroscopy and Brinell hardness testing of the castings indicated they met the requirements. There were no chemical requirements for nitrogen and aluminum contents in the proprietary specification. Charpy impact testing of several castings indicated low absorbed energy at $-40{ }^{\circ} \mathrm{C}$ (4-8 joules) and $100 \%$ brittle fracture surface, correlating with the tensile test results.

\section{Discussion}

Aluminum nitride embrittlement of heavy steel castings has been identified as a mechanism since at least 1947, as published by Lorig and Elsea $[3,5]$. The embrittlement shows up as poor tensile ductility and poor impact properties [3], but it is important to note that tensile strength and yield strength may still meet the required minimums of the ordering standard [5]. Another important point is that keel blocks tested from the same pour will likely not exhibit any problems because they are typically $25-32 \mathrm{~mm}$ wall thickness, resulting in much faster cooling rate than the bulk casting; in this way they are not representative of the casting for embrittlement assessment purposes [5, 7]. The embrittlement can appear in normalized structures, quenched and tempered martensitic microstructures [2, 3], martensitic stainless steels [3], and particularly as cracking in the heat affected zones of welded steel castings [5], as was observed in this work.

Aluminum nitrides are known to precipitate on the primary austenite solidification grain boundaries under certain conditions and provide a brittle pathway for cracking $[2-5,7]$. The principal variables affecting the embrittlement mechanism are cooling rate, aluminum content, and nitrogen content $[2-5,7]$. It is also known that a similar embrittlement can be active in steel by precipitation of aluminum borides, aluminum carbo-borides, alloy carbides, or these precipitates combined with ferrite at the grain boundaries $[2,3]$.

Aluminum is present in the steel normally as a residual from the deoxidation practice, and nitrogen can easily be dissolved in liquid steel from an uncontrolled atmosphere [4]. Aluminum nitrides precipitate at the primary solidification grain boundaries with C-curve kinetics, similar to chromium carbide precipitation (i.e., sensitization) in austenitic stainless steels or like pearlite formation in carbon steel normalization [5,7], hence the importance of cooling rate. The nose of the AlN precipitation curve is at approximately $1150-1250{ }^{\circ} \mathrm{C}$ with a critical cooling time of hundreds to thousands of seconds, depending on steel composition and residual aluminum and nitrogen contents $[5,7]$. Increasing aluminum content at a fixed nitrogen level decreases the time for precipitation [5, 7]. Once formed, AlN precipitates are not believed to dissolve in steel appreciably until above $1250{ }^{\circ} \mathrm{C}$; this explains why normal heat treatments of steels do not remove the embrittlement condition once developed [2].

It was found in green sand mold casting that limiting the residual aluminum content to $<0.08 \mathrm{wt} . \%$ and wall thickness to $<102 \mathrm{~mm}$ generally prevented AlN embrittlement with standard practices [5, 7]. However, AlN embrittlement has been observed in larger castings with $0.02-0.06 \mathrm{wt} . \%$ aluminum, with reported nitrogen contents from 36 to $176 \mathrm{ppm}[2,3,6]$, emphasizing the importance of cooling rate and that prevention cannot be achieved by chemistry alone.

The cooling rate of a casting is controlled by its size, its surface-area-to-volume ratio, the sand type, and casting rigging configuration [4]. Casting practice in the past, using green sand molds, was empirically developed to achieve at least the critical cooling rate for typical aluminum and nitrogen contents [5, 7]. More formal Hannerz charts showing acceptable cooling rates for avoidance of AlN embrittlement as a function of nitrogen and aluminum content were developed; however, these charts have been found to be non-conservative, and many foundries do not know or actually measure cooling rates [4]. In addition, nitrogen content is often not monitored because the analyzers are expensive and the analysis is too timeconsuming compared to the desired production schedule [5].

With the development of air-set sand molding using organic binders, the actual cooling rates in more recent practice have slowed. The air-set sands are more desirable because they provide for better cast dimensions, cleaner surfaces, and more accurate reproduction of fine details $[5,7]$. The slower cooling rates may be due to volatilization of the organic binders during pouring, which provide insulating vapor spaces in the mold walls [5, 7], and possibly due to exothermic reactions in these organically bonded sands [4]. The older, green sand molds are claybonded and provide greater thermal conductivity and higher cooling rates.

Because of these arising issues, a supplementary macroetch requirement for heavy castings was developed, taking advantage of the known AlN embrittlement mechanism of films along the primary solidification boundaries [5, 7]. The result was the current $\mathrm{S} 23$ supplementary requirement of ASTM A 703/A 703M, established after $1984[5,7]$. This procedure requires a hot $\mathrm{HCl}$ etch and rates the resulting grain boundary pattern based on degree of 
networking and width of the etched boundaries by comparison to reference images and a table provided in the standard [8]. A typical view of a severity level 5 macroetch from the current work is shown in Fig. 9. The primary solidification dendrite pattern is clearly visible. Severity levels $>4$ are considered suspect and must be evaluated further by mechanical testing; however, levels $<4$ can still exhibit measurable lowered properties [5]. It should be noted that this ASTM A 703 supplementary requirement applies only to castings with $>0.08 \mathrm{wt} . \%$ aluminum and to "heavy section castings," which are defined as a combination of $\geq 37 \mathrm{~mm}$ wall thickness and $455 \mathrm{~kg}$. In the current work, AlN embrittlement was found in much smaller castings.

Given the above, an immediate question is how are nitriding steels successfully processed? These steels, such as the Nitralloy alloys, have intentional aluminum contents around $1.0 \mathrm{wt} . \%$ expressly for the purpose of combining with nitrogen for case hardening [9]. Obviously, the nitrogen for case hardening is applied after forming, but one would expect significant residual nitrogen from the ingot casting process, as in any other steel, such that AlN embrittlement would be of concern. Ingots of these nitriding steels are most likely (1) homogenized after casting at high enough temperature to dissolve and break up the primary austenite AlN network, (2) continuously cast in sufficiently small cross sections to allow for fast cooling, or (3) hot rolled at temperatures where hot ductility can counteract the effects of any embrittlement as the AlN network is mechanically broken up.

\section{Experimentation}

Considering the foregoing history of aluminum nitride embrittlement, dozens of Type 6 and Type 9 castings from

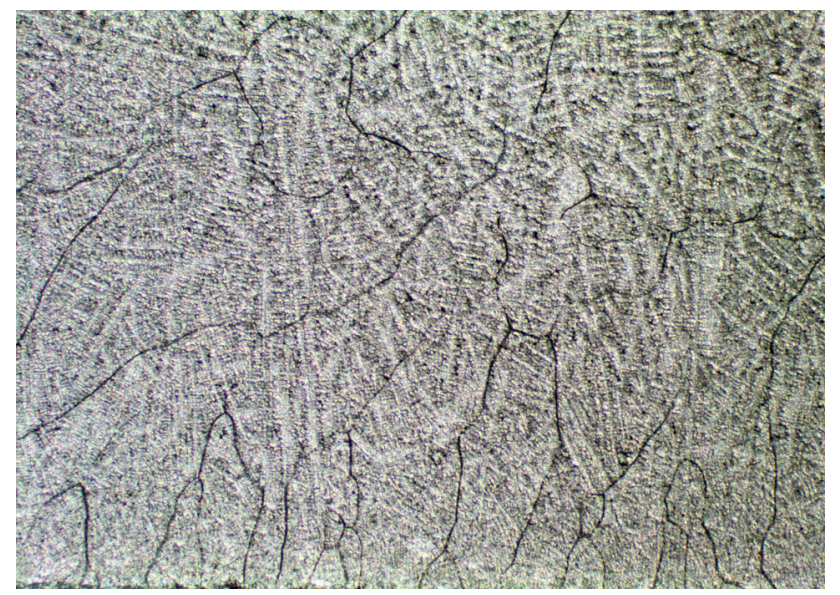

Fig. 9 Macro-etch specimen with severity level 5 using the ASTM A 703 procedure different heats were analyzed for nitrogen content, aluminum content, and degree of brittleness. Tensile specimens were prepared and tested per ASTM A 370. The elongation to fracture in a standard gage length was used as a measurement of degree of embrittlement. In addition, a secondary evaluation was developed by estimating \% brittle fracture appearance, similar to the $\%$ shear evaluation in ASTM E 23 for impact specimens. In parallel, the ASTM A 703 macro-etch test was conducted for correlation with the data.

Figure 10 shows the elongation to fracture as a function of aluminum content. The plot shows a trend to lower elongation (higher brittleness) with higher aluminum content, especially above $0.08 \mathrm{wt} . \%$, in agreement with the literature. This was especially true for the Type 9 heavier castings. Residual aluminum content for these heats ranged from 0.03 to $0.16 \mathrm{wt} . \%$. There was no clear trend for nitrogen content (Fig. 11), which ranged from 60 to $100 \mathrm{ppm}$. There was a clear trend to lower elongation when plotted as a function of the macro-etch severity level, per ASTM A 703 (Fig. 12).

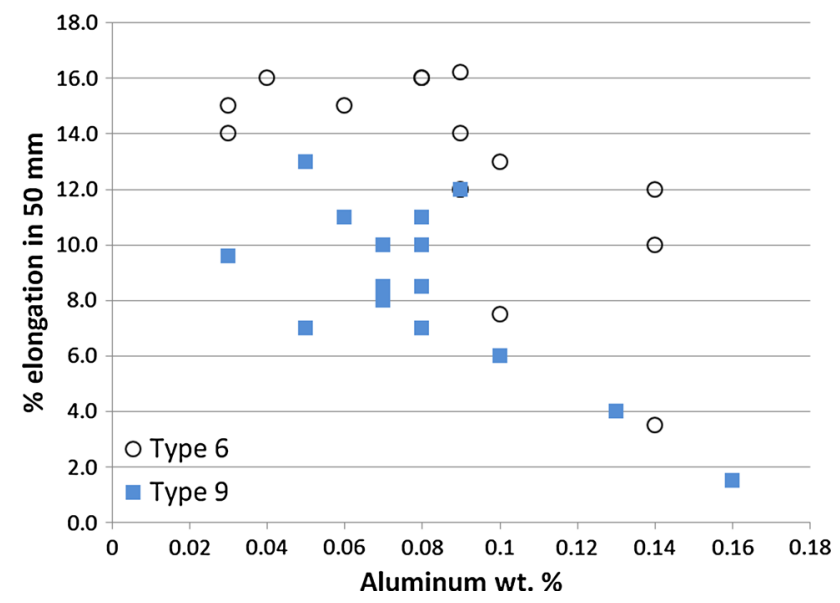

Fig. 10 Elongation as a function of aluminum content

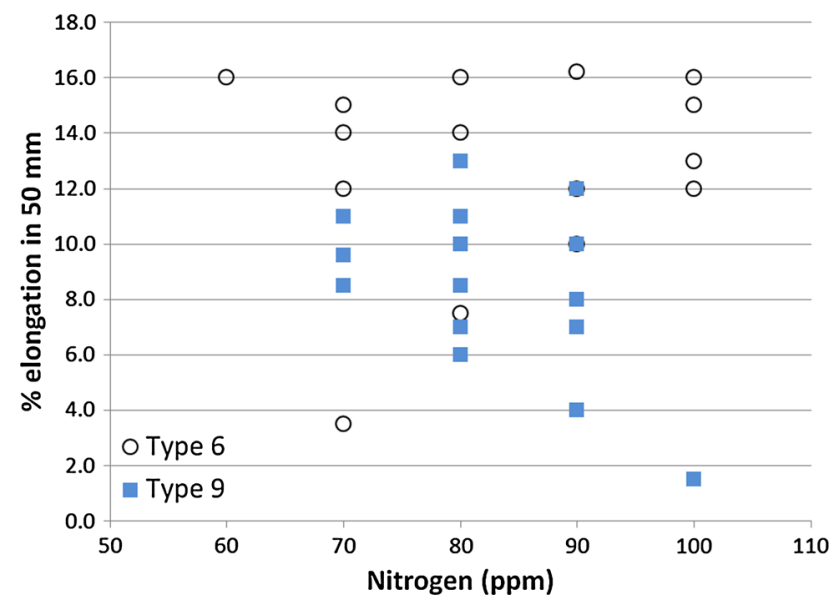

Fig. 11 Elongation as a function of nitrogen content 


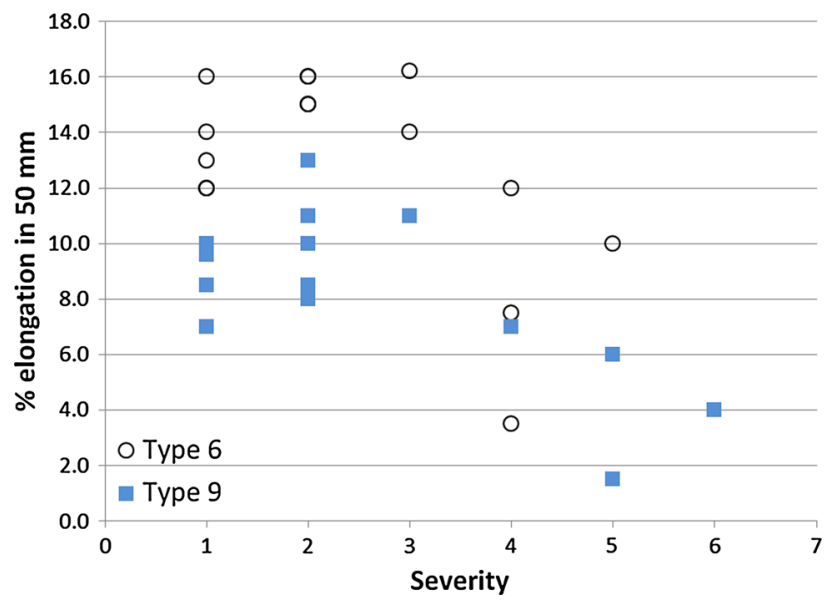

Fig. 12 Elongation as a function of severity level

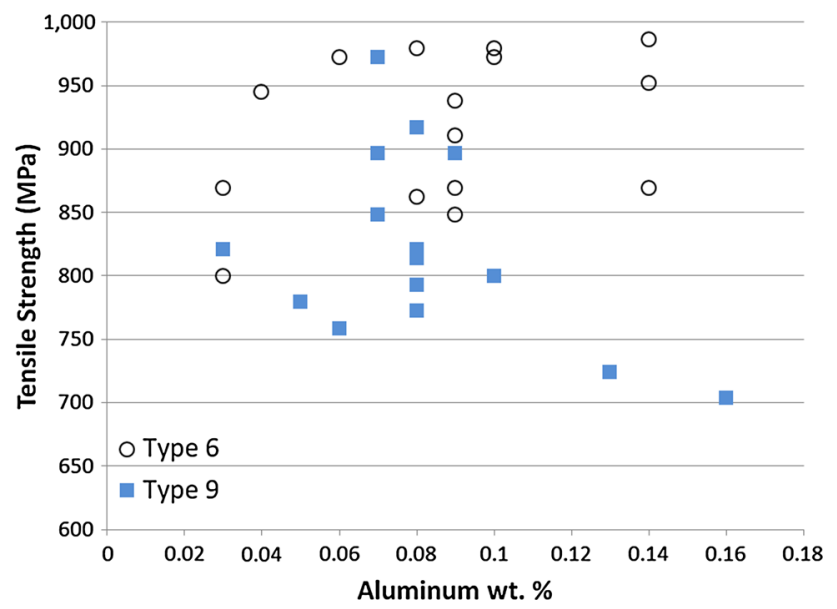

Fig. 13 Tensile strength as a function of aluminum content

The severity level illustrates the trend more distinctly since it combines the variables of aluminum content and cooling rate into one value; it evaluates the actual AIN networking present. The trend was significant at level 4 and above, consistent with the literature. Plots of brittle fracture appearance as a function of severity level were essentially identical to Fig. 12. It is interesting to observe that the same set of tests presented very little, if any, change in tensile strength as a function of aluminum content (Fig. 13). The scatter remained consistent, except for the heavier, Type 9, castings above $0.12 \mathrm{wt} . \%$ aluminum, where there was somewhat of a drop below the remainder of the scatter. This is again consistent with the literature reports.

\section{Conclusions}

The castings fractured due to aluminum nitride embrittlement in combination with the welding thermal expansion/contraction and phase transformation stresses. The three main factors influencing aluminum nitride embrittlement are aluminum concentration, nitrogen concentration and the cooling rate of the casting. The data presented here suggest nitrogen content is less influential than the other two variables. Aluminum has been suggested to be controlled to $0.08 \mathrm{wt} . \%$ or less to prevent AlN embrittlement; this recommendation is supported by the data presented in this article. However, care must be taken in making this recommendation to foundries, since cooling rate cannot be neglected.

The severity rating by the macro-etch supplementary requirement S23 in ASTM A 703 has been available for decades to assess heavy castings for AlN embrittlement, and it can be applied to smaller steel castings. This work showed that it is a reliable way of screening castings and illustrated trends in brittleness better than chemistry alone. It should be used as a purchasing requirement in any situation where cooling rates are not known or controlled, or if aluminum or nitrogen concentrations are suspected to be uncontrolled.

It has been suggested that AlN embrittlement may be avoided by titanium additions, since Ti has a higher affinity for nitrogen and would bind it up in more favorable morphology precipitates. Another suggestion has been conducting a homogenizing heat treatment at approximately $1316{ }^{\circ} \mathrm{C}$ for $3-4 \mathrm{~h}$ after the casting has cooled [3]. The effectiveness of these recommendations could not be assessed within the scope of this project.

\section{References}

1. ASTM E 112-2013, Standard Test Methods for Determining Average Grain Size (ASTM International, West Conshohocken, PA, 2013)

2. M. Blair, Brittle Fracture in a WCB Steel Casting, Steel Founders Society of America Technical Services Report \#123 (1995)

3. D.E. Dutcher, Understanding rock candy fracture in steel castings. Mod. Cast. 89(2), 46-47 (1999)

4. C. Monroe, R. Huff, Prediction of aluminum nitride embrittlement in heavy section steel castings. Int. J. Metalcast. 4, 27-33 (2010)

5. W.C. Banks, Avoiding Aluminum Nitride Embrittlement in Steel Castings for Valve Components, pamphlet (Flowserve/Edward Valves, Irving, TX, 1984) (reprinted 2003)

6. W.T. Becker, R.J. Shipley (eds.), ASM Handbook Vol. 11: Failure Analysis \& Prevention (ASM International, Materials Park, OH, 2002), p. $145 \& 353$

7. W.C. Banks, Avoiding aluminum nitride embrittlement in steel castings for valve components, in Proceedings of the 1985 Pressure Vessel \& Piping Conference (PVP vol 98-2) (1985) p. 219-224

8. ASTM A703/A703M-2017, Standard Specification for Steel Castings, General Requirements for Pressure-Containing Parts (ASTM International, West Conshohocken, PA, 2017)

9. H. Chandler, Heat Treater's Guide: Practices and Procedures for Irons and Steels (Materials Park, OH, ASM International, 1995), p. 63 